\title{
Analisis Manajemen Risiko Material dengan Metode Zero-One (Studi Kasus : Pada Proyek Pembangunan Apartemen Tamansari Amarta Yogyakarta)
}

\author{
Widi Hartono'), Sugiyarto ${ }^{2)}$, dan Eva Kumala Wikan Prasodjo ${ }^{3)}$ \\ 1) Pengajar Fakultas Teknik, Prodi Teknik Sipil, Universitas Sebelas Maret \\ 2) Pengajar Fakultas Teknik, Prodi Teknik Sipil, Universitas Sebelas Maret \\ 3) Mahasiswa Fakultas Teknik, Prodi Teknik Sipil, Universitas Sebelas Maret \\ Jl. Ir. Sutami 36A, Surakarta 57126; Telp. 0271-634524. Email: eva033@yahoo.com
}

\begin{abstract}
The process of constructing an apartment is one of the ways to overcome the increasing of residence issue, particularly in several cities which have a limitation of land problem. The analysis of material risk management on the apartment construction which affects the time and the cost is highly required to consider. This research aims to obtain the dominant risks that occur and the most dominant risk management efforts. The analysis of risk load uses Zero One method, while the determination of dominant risk uses risk index measurement. This research result shows that from the chosen 13 risk variables, the most dominant risk on the time impact is the weakness of controlling cost system and cost, which causing lateness and addition of cost with the risk index average reached 5.597. Besides, the most dominant risk on the cost impact is the inefficient use of the material, bence it disserves the contractor with the average risk index of 6.686
\end{abstract}

Key words: analysis of risk, Zero-One, risk index.

\begin{abstract}
Abstrak
Pembangunan apartemen merupakan salah satu cara untuk menyelesaikan permasalahan meningkatnya kebutuhan hunian terutama di beberapa kota yang memiliki masalah keterbatasan lahan. Dalam pembangunan apartemen dibutuhkan analisa manajemen risiko material untuk mengetahui risiko yang berdampak terhadap waktu dan biaya. Penelitian ini bertujuan untuk mendapatkan risiko-risiko material yang dominan terjadi dan upaya penanganan dari risiko yang paling dominan. Analisis penentuan bobot risiko menggunakan metode Zero-One sedangkan penentuan risiko dominan menggunakan perhitungan risk index. Hasil riset ini menunjukan bahwa dari 13 variabel risiko yang dipilih risiko yang paling dominan terhadap dampak waktu adalah sistem pengendalian biaya dan waktu yang lemah menyebabkann keterlambatan material dan penambahan biaya dengan rata-rata risk index sebesar 5.597. Sedangkan risiko yang paling dominan terhadap dampak biaya adalah pemanfaatan material yang kurang efisien sehingga merugikan kontraktor dengan rata-rata risk index sebesar 6.686
\end{abstract}

Kata kunci: analisa risiko, Zero-One, risk index.

\section{PENDAHULUAN}

Pembangunan apartemen merupakan salah satu langkah yang digunakan pemerintah untuk mencukupi kebutuhan hunian di kota-kota besar yang memiliki masalah keterbatasan lahan, salah satunya adalah Yogyakarta. Proyek konstruksi dapat selesai dengan baik apabila memiliki suatu manajemen material yang baik, karena material merupakan komponen pokok konstruksi yang harus tersedia sesuai dengan spesifikasi teknis yang sudah ditentukan dalam kontrak.

Proyek pembangunan apartemen merupakan proyek dengan risiko tinggi, mengingat lamanya pekerjaan dan tingginya struktur yang dikerjakan. Apartemen Tamansari Amarta berlokasi di kawasan Sleman, Yogyakarta, bangunan ini memiliki 16 lantai dan berada di area seluas 6366 meter persegi dengan biaya yang dibutuhkan kurang lebih 300 milyar. Proyek konstruksi ini dimulai pada bulan Mei tahun 2017 dan selesai pada bulan agustus 2019. Karena keterbatasan waktu dan besarnya pekerjaan maka dibutuhkan analisis risiko. Karena, semakin besar nilai proyek akan sebanding dengan besarnya risiko yang mungkin terjadi..

Analisis risiko dilakukan untuk mengetahui risiko yang dominan terjadi dalam pembangunan proyek Apartemen Tamansari Amarta. Analisa ini mengggunakan metode Zero-One untuk menentukan bobot risiko, selanjutnya penentuan bobot risiko ditentukan dengan perhitungan risk index. Risiko dominan merupakan risiko dengan nilai risk index tertinggi. Setelah mengetahui risiko dominan selanjutnya akan ditentukan upaya penanganan yang digunakan untuk merespons risiko dengan menghitung dan menentukan level risiko masing-masing variabel.

\section{LANDASAN TEORI}

Iman Soeharto (2001) menyatakan bahwa risiko adalah kemungkinan terjadinya peristiwa di luar yang diharapkan. Vaughan (1997) juga berpendapat bahwa dasar dari fungsi manajemen risiko adalah merancang dan menerapkan prosedur untuk meminimalkan dampak negatif jika risiko terjadi. Menurut Wulfram (2004) manajemen material adalah suatu pendekatan organisasional untuk menyelesaikan permasalahan material yang memerlukan kombinasi 
kemampuan dan teknis.Untuk menekankan pentingnya manajemen material ialah dengan mengingat kenyataan bahwa lebih dari separuh pengeluaran proyek pada umumnya dialokasikan untuk material (Dennis Lock, 1994). Oleh sebab itu diperlukan pengendalian yang baik pada proses pengadaan bahan material. Apartemen merupakan beberapa kamaryang diperuntukan sebagai tempat tinggal terdapat di dalam suatu bangunan yang memilki kamar atau ruangan-ruangan lain semacam itu. Penelitian ini menggunakan metode Zero-One dalam proses penentuan bobot risiko. Metode Zero-One adalah suatu cara pengambilan keputusan yang bertujuan untuk menetukan prioritas fungsi-fungsi (kriteria) (Hutabarat,1995). Cara pelaksanaan metode Zero-One dengan mengumpulkan fungsi-fungsi dalam tingkatan yang sama, lalu disusun dalam suatu matriks Zero-One persegi. Kemudian dilakukan penilaian fungsi-fungsi secara berpasangan. Fungsi akan diberikan nilai 1 apabila dianggap lebih berisiko, diberikan nilai 0 apabila dianggap kurang berisiko dan diberi tanda $\mathrm{x}$ apabila masing-masing fungsi memiliki nilai yang sama, Nilai pada matriks kemudian dijumlah menurut baris yang dikumpulkan pada kolom jumlah. Penentuan bobot akan dihitung dengan cara angka ranking yang dimiliki dibagi dengan jumlah angka ranking selanjutnya dikalikan 100. Putri (2016) menyatakan bahwa risiko dominan yang dianalisa menggunakan metode Analyical Hierarcby Process pada proyek pembangunan Hartono Lifestyle Mall Yogyakarta adalah produktivitas tenaga kerja rendah, sistem pengendalian biaya dan waktu yang lemah, dan pekerjaan lain yang mendahului terlambat.

Berikut ini merupakan 13 variabel yang digunakan dalam penelitian :

V1. Kesalahan dalam memprediksi kondisi lapangan, cuaca, dan kejadian yang akan datang.

V2. Kesalahan dalam merencanakan lingkup pekerjaan

V3. Sering terjadi perpindahan material

V4. Kesalahan dalam mengestimasi dan merencanakan anggaran belanja untuk material

V5. Percepatan jadwal

V6. Kurang akurat dan teliti dalam pembuatan jadwal

V7. Pemanfaatan material yang kurang efisien sehingga merugikan kontraktor

V8. Sistem pengendalian biaya dan waktu yang lemah sehingga menyebabkan keterlambatan dan penambahan biaya

V9. Keterlambatan pengiriman material

V10. Akses transportasi pengiriman yang kurang baik

V11. Tempat penyimpanan material yang kurang luas

V12. Kerusakan alat pengangkut material

V13. Lambatnya penganganan pada loading area

\section{METODE}

Metode yang digunakan dalam penelitian ini adalah metode studi kasus. Tahapan penelitian meliputi tahap persiapan dengan melakukan identifikasi masalah dan survey lokasi, kegiatan pengumpulan data yaitu data primer yang diperoleh dengan pembagian kuisioner dan wawancara, serta data sekunder yang diperoleh dengan studi literatur. Berdasarkan data hasil kuisioner tahap 1 dianalisa menggunakan metode Zero-One untuk mengetahui risiko dengan bobot tertinggi, selanjutnya dari hasil kuisioner tahap 2 dianalisa level risiko untuk mengetahui upaya penanganan yang dibutuhkan berdasarkan tingkat risiko. Selanjutnya dilakukan analisa mengenai risk index menggunakan hasil analisa bobot risiko dan hasil kuisioner tahap 2 untuk mengetahui risiko yang paling dominan. Lalu akan ditentukan upaya penanganan yang digunakan untuk merespons risiko yang dominan

\section{HASIL DAN PEMBAHASAN}

Berdasarkan hasil analisa yang telah dilakukan, penelitian ini bertujuan untuk menemukan risiko dominan dengan nilai risk index tertinggi pada proyek pembangunan Apartemen Tamansari Amarta Yogyakarta berdasarkan penilaian yang telah diberikan sampel, didapatkan hasil sebagai berikut :

1. Hasil analisa bobot yang telah dilakukan dengan metode Zero-One risiko menunjukan bahwa sistem penge dalian biaya dan waktu yang lemah menyebabkan keterlambatan dan penambahan biaya merupakan variabel dengan rata-ratabobot tertinggi 88.9. Berdasarkan data, semua sampel sepakat bahwa risiko ini berdampak besar terhadap waktu dan biaya proyek. Untuk mengatasi risiko ini pihak kontraktor seharusnya mengoppttimalkan kinerja staff dengan memberikan pelatihan mengenai manajemen material dan manajemen risiko supaya staff dapat mempersiapkan strategi yang baik untuk mengatasi sistem yang lemah dan menghindari keterlambatan serta meminimalisir penambahan biaya. Hasil analisa bobot risiko lengkapnya dapat dilihat pada Tabel 1. 
Tabel 1. Hasil Analisa Bobot Risiko

\begin{tabular}{clcc}
\hline No. & \multicolumn{1}{c}{ Variabel } & Jumlah Bobot & Rata-Rata Bobot \\
\hline 1. & $\begin{array}{l}\text { Kesalahan dalam memprediksi kondisi lapangan, cuaca, dan kejadian } \\
\text { yang akan datang. }\end{array}$ & 361.5 & 40.2 \\
\hline 2. & Kesalahan dalam merencanakan lingkup pekerjaan & 569.2 & 63.2 \\
\hline 3. & Sering terjadi perpindahan material & 338.5 & 37.6 \\
\hline 4. & $\begin{array}{l}\text { Kesalahan dalam mengestimasi dan merencanakan anggaran belanja } \\
\text { untuk material }\end{array}$ & 753.8 & 83.8 \\
\hline 5. & Percepatan jadwal & 238.5 & 26.5 \\
\hline 6. & Kurang akurat dan teliti dalam pembuatan jadwal & 576.9 & 64.1 \\
\hline 7. & $\begin{array}{l}\text { Pemanfaatan material yang kurang efisien sehingga merugikan kon- } \\
\text { traktor }\end{array}$ & 730.8 & 81.2 \\
\hline 8. & $\begin{array}{l}\text { Sistem pengendalian biaya dan waktu yang lemah sehingga me- } \\
\text { nyebabkan keterlambatan dan penambahan biaya }\end{array}$ & 800.0 & 88.9 \\
\hline 9. & Keterlambatan pengiriman material & 515.4 & 57.3 \\
\hline 10. & Akses transportasi pengiriman yang kurang baik & 430.8 & 47.9 \\
\hline 11. & Tempat penyimpanan material yang kurang luas & 153.8 & 17.1 \\
\hline 12. & Kerusakan alat pengangkut material & 584.6 & 65.0 \\
\hline 13. & Lambatnya penganganan pada loading area & 230.8 & 25.6 \\
\hline
\end{tabular}

2. Hasil analisa level risiko yang telah dianalisa menggunakan hasil kuisioner tahap 2 menunjukan bahwa a. Berdasarkan perhitungan level risiko dominan yang berpengaruh terhadap waktu proyek, risiko dengan level tertinggi adalah keterlambatan pengiriman material dengan level risiko high risk, sedangkan 12 variabel risiko yang lain tergolong pada level medium risk sesuai dengan Gambar 1.

b. Berdasarkan perhitungan level risiko dominan yang berpengaruh terhadap biaya proyek, semua variabel risiko dapat digolongkan p pada level medium risk sesuai dengan Gambar2.

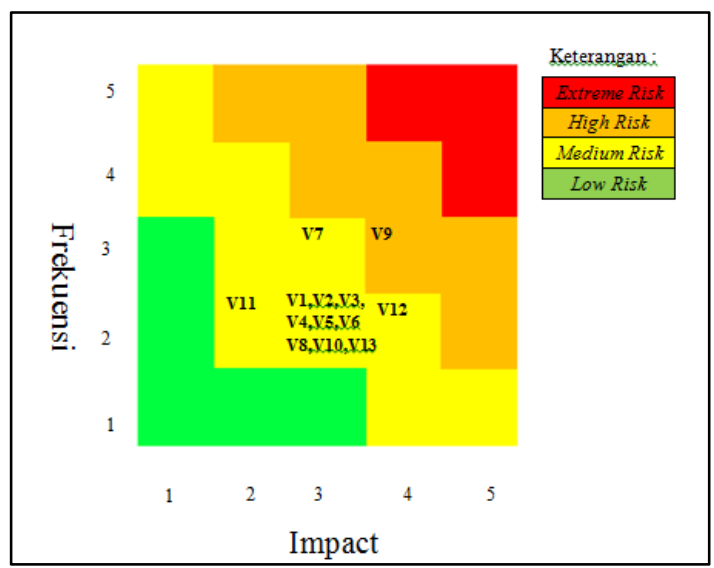

Gambar 1.

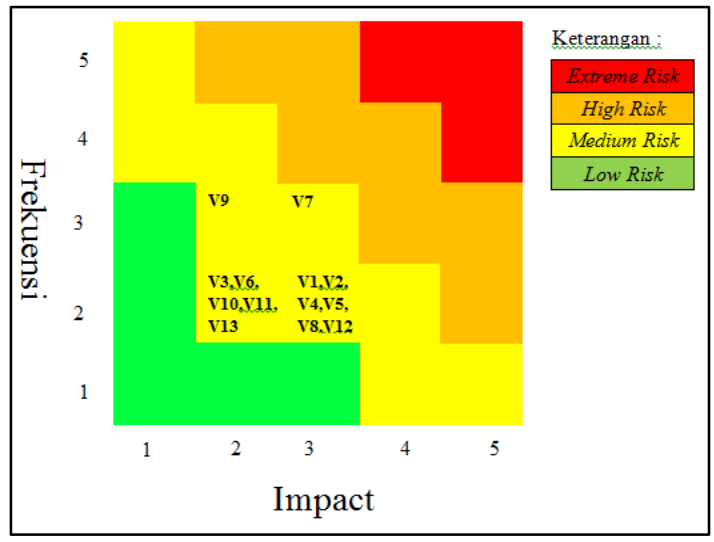




\section{Gambar 2.}

3. Hasil analisa risk index yang telah dianalisa menggunakan data hasil analisa bobot menggunakan metode Zero-One dan kuisioner tahap 2 yang telah diisi oleh sampel menunjukan bahwa :

a. Risiko dominan yang berpengaruh terhadap waktu proyek adalah sistem pengendalian biaya dan waktu yang lemah menyebabkan keterlambatan dan penambahan biaya dengan nilai risk index 559.7. Berdasarkan data kuisioner tahap 2, risiko ini memiliki probabilitas yang rendah, namun dampak yang disebabkan termasuk dalam kategori sedang. Hal ini selaras dengan data sekunder berupa laporan bulanan dari proyek yang menunjukkan bahwa terdapat keterlambatan 1-2 minggu pada proses pekerjaan bekisting vertikal lantai 2-16 dan bekisting horizontal lantai 6- 11. Berdasarkan hasil analisa level risiko, risiko ini tergolong pada tingkat medium risk. Upaya penanganan yang dapat dilakukan dengan melakukan perhitungan mengenai keterlambatan dan kerugiannya, untuk mengejar keterlambatan tersebut kontraktor dapat melakukan penambahan jam kerja, namun apabila penambahan jam kerja dirasa kurang dapat dilakukan dengan penambahan tenaga kerja yang dapat dilakukan dengan estimasi terlebih dahulu untuk meminimalisir penambahan biaya yang kurang efisien.

b. Risiko dominan yang berpengaruh terhadap biaya proyek adalah pemanfaatan material yang kurang efisien sehingga merugikan kontraktor dengan nilai risk index 668.6. Pemborosan material terjadi di beberapa aspek, Pada penyimpanan material khususnya material pasir, disimpan pada ruangan terbuka dan tidak diberi sekat di beberapa sisinya, hal ini menyebabkan apabila terjadi hujan maka pasir tersebut ikut hanyut dengan air hujan dan mengalami penurunan jumlah. Selain itu, pada proses pendistribusian material terjadi kesalahan pada proses pengangkutan dari loading area ke lantai kerja, pada saat pengkaitan tali tower crane ke material terjadi kesalahan karena tidak sesuai dengan standard operasional yang menyebabkan material jatuh dan rusak sehingga tidak dapat digunakan sebagaimana mestinya, pada pekerjaan pleseter juga dapat ditemui pemborosan material yang disebabkan karena pekerja yang kurang terampil, hasil pekerjaan plester dianggap kurang efisien karena banyak adukan plester yang tercecer di lantai kerja dan tidak menempel pada dinding. Berdasarkan hasil analisa, risiko ini tergolong pada level medium risk dengan upaya penanganan bagian pengadaan sebaiknya memberi material cadangan yang disediakan dengan estimasi waktu yang baik untuk menghindari keterlambatan pengiriman material, serta dalam pendistribusiannya dilakukan secara bertahap untuk meminimalisir pemborosan material dan memudahkan pengawasan. Perbaikan metode konstruksi juga diperlukan untuk meminimalisir kesalahan dalam distribusi material khususnya pada saat pengangkatan material menggunakan tower crane supaya tidak terjadi kerusakan material.

\section{SIMPULAN}

Data hasil pengujian, analisis data, dan pembahasan terhadap hasil dari penelitian analisis Manajemen Risiko Material dengan Metode Zero-One, dapat ditarik simpulan sebagai berikut:

Dalam penelitian ini terdapat 13 variabel risiko, risiko yang paling dominan terhadap dampak waktu adalah sistem pengendalian biaya dan waktu yang lemah menyebabkann keterlambatan dan penambahan biaya dengan rata-rata risk index sebesar 5.597. Sedangkan risiko yang paling dominan terhadap dampak biaya adalah pemanfaatan material yang kurang efisien sehingga merugikan kontraktor dengan rata-rata risk index sebesar 6.686. Tindakan penanganan untuk merespon risiko sistem pengendalian biaya dan waktu yang lemah menyebabkan keterlambatan dan penambahan biaya adalah menciptakan jadwal pengadaan material dan jadwal pekerjaan yang realistik, rinci, dan jelas, serta memberikan penambahan jam kerja dan penambahan tenaga kerja sesuai dengan estimasi waktu dan biaya, sedangkan tindakan penanganan untuk merespon risiko pemanfaatan material yang kurang efisien adalah memberikan material cadangan secara bertahap untuk memudahkan pengawasan bahan material serta melakukan perbaikan metode konstruksi.

\section{REKOMENDASI}

1. Perlu penelitian lebih lanjut mengenai risiko material dari proyek yang ditangani oleh kontraktor BUMN lain atau kontraktor swasta.

\section{UCAPAN TERIMAKASIH}

Ucapan terima kasih pertama ditujukan kepada Allah SWT atas limpahan rahmat dan nikmatnya. Selanjutnya kepada Bapak Widi Hartono, S.T., M.T. dan Bapak Ir. Sugiyarto, M.T. selaku dosen pembimbing yang telah memberi arahan dan masukan dalam penelitian ini. 


\section{REFERENSI}

Dennis Lock. 1984. "Project Management, Third Edition”. Jakarta: Erlangga.

Emmett J Vaughan. 1997. "Risk Management”. New York: John Wiley.

Hutabarat, J. 1995. "Diktat Rekayasa Nilai (Value Engineering)”. Institut Teknologi Nasional. Malang

Iman Soeharto. 2001. "Manajemen Proyek (Dari Konseptual Sampai Operasional)”. Jakarta: Erlangga.

Wilfridus J Sabarija Poerwadarminta. 1991. "Kamus Umum Bahasa Indonesia”. Jakarta: Balai Pustaka.

Wulfram I Ervianto. 2004. "Teori-Aplikasi Manajemen Proyek Konstruksi”. Yogyakarta: ANDI.

Putri Pratitasari. 2015. "Analisis Risiko Konstruksi Struktur Bawah pada Proyek Pembangunan Hartono Lifestyle Mall Yogyakarta dengan Metode Analytical Hierarchy Process (AHP)”. Program Studi Teknik Sipil Fakultas Teknik Universitas Sebelas Maret, Surakarta. 